\title{
Management of Complicated Crown-Root Fracture by Fragment Reattachment Using Fibre-Post: An Aesthetic Alternative
}

\author{
Dr. Reema Malik ${ }^{1}$, Dr. Amit Raj ${ }^{2}$, Dr. Rajul Vivek ${ }^{3}$ \\ ${ }^{I}$ (Department of Conservative Dentistry And Endodontics, Faculty Of Dental Sciences, Ims, Bhu, India) \\ ${ }_{2}^{2}$ (Department of Prosthodontics, Faculty of Dental Sciences, Ims, Bhu, India) \\ ${ }^{3}$ (Phd Scholar, Faculty of Dental Sciences, Ims, Bhu, India)
}

\begin{abstract}
The advances in adhesive dentistry have allowed dentists to use the patient's own fragment to restore the fractured tooth. The present case report describes management of a complicated fracture of maxillary right central incisor treated endodontically, followed by reattachment of the same fragment using fiber post. Reattachment of fractured tooth fragments offers a viable restorative alternative, immediately restores tooth function for the clinician because it restores tooth function and esthetics with the use of a very conservative and cost-effective approach.
\end{abstract}

Keywords: Crown fracture, fiber post, reattachment, complicated crown fracture, trauma

\section{Introduction}

Trauma to the anterior teeth is relatively common occurrence. It has been reported that prevalence of trauma involving upper central incisor is $37 \%$. These fractures subsequently lead to aesthetic, functional, and phonetic problems. Management of the dental trauma requires a comprehensive and accurate diagnostic and treatment plan. (1) Choosing a treatment approach for a complicated crown fracture depends on the level and position of tooth fracture line, availability of displaced tooth fragments, type of occlusion, and prognosis. $(2,3)$ Improvements in adhesive dentistry have enabled a conservative approach by reattachment of the fragment when it is present or reconstruction with composite resins.

Chosack and Eildeman published the first case report on reattachment of a fractured incisor fragment in 1964. (4) Tennery was the first to report the reattachment of a fractured fragment using acid-etch technique. Subsequently, Starkey and Simonsen (5) have reported similar cases. This technique is a simple conservative approach to provide functional rehabilitation and economically acceptable and it can offer good and long-lasting esthetics (as the original tooth anatomic form, color, and surface texture are maintained). (6) The present case report describes a case of complicated crown-root fracture managed by fragment reattachment using fibre-post.

\section{Case Report}

A 35 year old male patient reported to the department of conservative dentistry and endodontics with a chief complaint of fractured maxillary right central and lateral incisor and maxillary left central incisor following trauma three days ago due to fall. No significant hard or soft-tissue injury, other than tooth fracture, was observed. Clinical (figure 1)and radiographic examination revealed that it was complicated crown-root fracture in an oblique direction from labial to lingual in occlusal direction related to maxillary right central incisor. An oblique fracture of the palatal portion extended subgingivally and fractured fragment partially attached to the crown structure. Right maxillary incisor showed mesioangular incisal chipping and left maxillary central incisor showed Ellis Class II fracture. A diagnosis of complicated crown fracture (involving the pulp chamber) - Ellis Class III with respect to maxillary right central incisor was made. As the fracture was a complicated one, a decision of single-visit endodontic treatment was taken. Since the fractured fragments were intact, with slight attachment palatally, reattachment of the same fragment was planned.

After taking informed consent from the patient and administration of local anesthesia, access was gained through palatal region. The coronal pulp tissue was removed and the chamber irrigated with 5.25\% sodium hypochlorite $(\mathrm{NaOCl})$ and normal saline. Initial negotiation of the root canal was performed with a no. $10 \mathrm{k}$-file and an initial working length radiograph was taken. The root canal was cleaned with $17 \%$ ethylenediaminetetraacetic acid (EDTA) and 5.25\% sodium hypochlorite and shaped with hand protaper files. The root canal was dried with absorbent paper points obturated with $2 \%$ gutta percha points and zinc oxide eugenol sealer. Post-obturation IOPA radiograph was taken and root canal filling was found to be satisfactory.

After completion of the endodontic treatment, the root canal was prepared for the post placement by removing the gutta percha from the coronal two-thirds of the canal with peeso reamers (drill size 2). Bevels are placed on the tooth and the fractured fragment, in order to enhance the retention. The fibre post (Dentply Tulsa, Johnson city, US) was tried in the canal and adjusted to the desired length. Space was also prepared in the pulp chamber of the palatal fragments for receiving the coronal portion of the post. The alignment of the coronal 
fragment was verified with the post in situ. The root canal was then etched with $37 \%$ ortho phosphoric acid (3M ESPE) for 15 seconds, rinsed, and blot dried with paper points, and bonding agent (Adper Single Bond, 3M ESPE) was applied.The post was then luted in the canal using dual cured resin luting cement (Ivoclar Vivadent). The inner portion of the coronal fragment was similarly etched and bonded to the tooth using flowable composite resin (Ivoclar Vivadent) after proper shade matching. Excess paste along the margins was removed using blade and visible light curing was done for 20 seconds each on labial and palatal side. Maxillary right lateral incisor and left central incisor were also restored with microhybrid composite (Filtek Z250 ${ }^{\mathrm{TM}} 3 \mathrm{M}$ ESPE). The restored surface was finished and polished (Sof-Lex ${ }^{\mathrm{TM}}$ disks 3M ESPE) (figure 2).Final evaluation for occlusion and esthetics was done. Finally, tooth was restored with porcelain fused to metal crown (figure 3). Clinical and radiographic examinations were carried out after 1 month, 3 months, and 6 months and the tooth responded favourably.

\section{Discussion}

Protection of mechanical and functional integrity is one of the most important factors in the restoration of traumatized anterior teeth. There are many different treatment modalities for restoration of traumatized teeth such as composite resin restorations with and without pins and prosthetic repair. (7) Whenever the fractured fragment is available intact, the reattachment of the fragment has to be the most desired treatment.

Reattachment of fragments involving enamel and dentin has been found to be satisfactory after 1 year. (8) Incisal fractures of anterior teeth have been successfully treated by reattachment. (9) Complicated fractures involving pulp have been treated by reattachment with post and core. (10) With advances in adhesive dentistry, the process of fragment reattachment has become simplified and more reliable. (11) This technique has several advantages such as maintenance of original enamel translucency, similar wear rates as compared to the adjacent teeth, and minimal chair time needed.

Recently, different types of post materials have been introduced into the dental practice such as carbon fiber, quartz, and glass fiber. (12) With the recent improvements in the dental materials, resin-based restorative materials with tooth-colored fiber post are of choice because of several advantages such as a suitable elastic modulus, esthetics, good bonding between post and cement, lower chair time, and minimal tissue removal. (13, 14) The use of a fiber post with fractured teeth, as it interlocks the two fragments, minimizes the stress on the reattached tooth fragment. $(13,14)$ Follow-up visits are critically important for all traumatic injuries. The patient should be followed for 3, 6, 12 months and yearly for 5 years. Esthetics, tooth mobility, and periodontal status should be confirmed both clinically and radiographically at these follow-up visits. This paper signifies that different tooth fragments can be successfully treated by using a fiber-supported post system with dual curing resin.

\section{Conclusion}

This case report presented a successful esthetic management of a complicated oblique crown-root fracture. The agglutination method of the fractured part, using fiber-supported post system, is an effective and conservative treatment option that provides regaining esthetic and functional completeness for the patient.

\section{Reference}

[1]. Bruschi-Alonso RC, Alonso RC, Correr GM, Alves MC, Lewgoy HR, Sinhoreti MA, et al. Reattachment of anterior fractured teeth: Effect of materials and techniques on impact strength. Dent Traumatol 2010;26:315-22

[2]. Aggarwal V, Logani A, Shah N. Complicated crown fractures - management and treatment options. Int Endod J 2009;42:740-53.

[3]. Villat C, Machtou P, Naulin-Ifi C. Multidisciplinary approach to the immediate esthetic repair and long-term treatment of an oblique crown-root fracture. Dent Traumatol 2004;20:56-60

[4]. Reis A, Loguercio AD, Kraul A, Matson E. Reattachment of fractured teeth: A review of literature regarding techniques and materials. Oper Dent. 2004; 29:226-33

[5]. Simonsen RJ. Restoration of a fractured central incisor using original tooth fragment. J Am Dent Assoc. 1982; 105:646-48

[6]. Arapostathis K, Arhakis A, Kalfas S. A modified technique on the reattachment of permanent tooth fragments following dental trauma. Case report. J Clin Pediatr Dent 2005;30:29-34

[7]. Ozel E, Kazandag MK, Soyman M, Bayirli G. Two-year follow-up of fractured anterior teeth restored with direct composite resin: Report of three cases. Dent Traumatol 2008;24:589-92.

[8]. Hegede RJ Tooth fragment reattachment - an esthetic alternative: Report of a case. J Indian Soc Pedod Prev Dent 2003; 21:117-9

[9]. Oz IA, Haytaç MC, Toroglu MS. Multidisciplinary approach to the rehabilitation of a crown-root fracture with original fragment for immediate esthetics: a case report with 4-year follow-up. Dent Traumatol. 2006 ;22:48-52.

[10]. Lehl G, Luthra R. Reattachment of fractured fragments of maxillary central incisors report of a case. J Indian Soc Pedo Prev Dent 2004;22:54-5

[11]. Wolcott J, Averbach RE. Management of complicated crown fractures: tooth fragment reattachment. Compend Contin Educ Dent 2002;23:520-4, 26, 28.

[12]. Asmussen E, Peutzfeldt A, Heitmann T. Stiffness, elastic limit, and strength of newer types of endodontic posts. J Dent 1999;27:275-8.

[13]. Torabi K, Fattahi F. Fracture resistance of endodontically treated teeth restored by different FRC posts: an in vitro study. Indian J Dent Res 2009;20:282-7.

[14]. Akkayan B. An in vitro study evaluating the effect of ferrule length on fracture resistance of endodontically treated teeth restored with fiber-reinforced and zirconia dowel systems. J Prosthet Dent 2004;92:155-62 


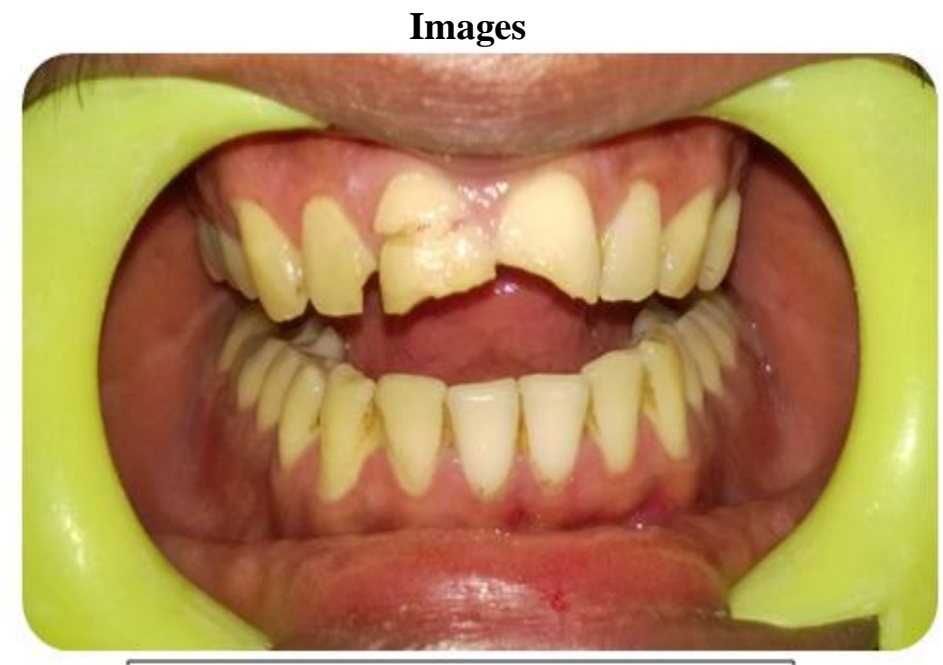

Fig 1 Pre-operative Clinical view

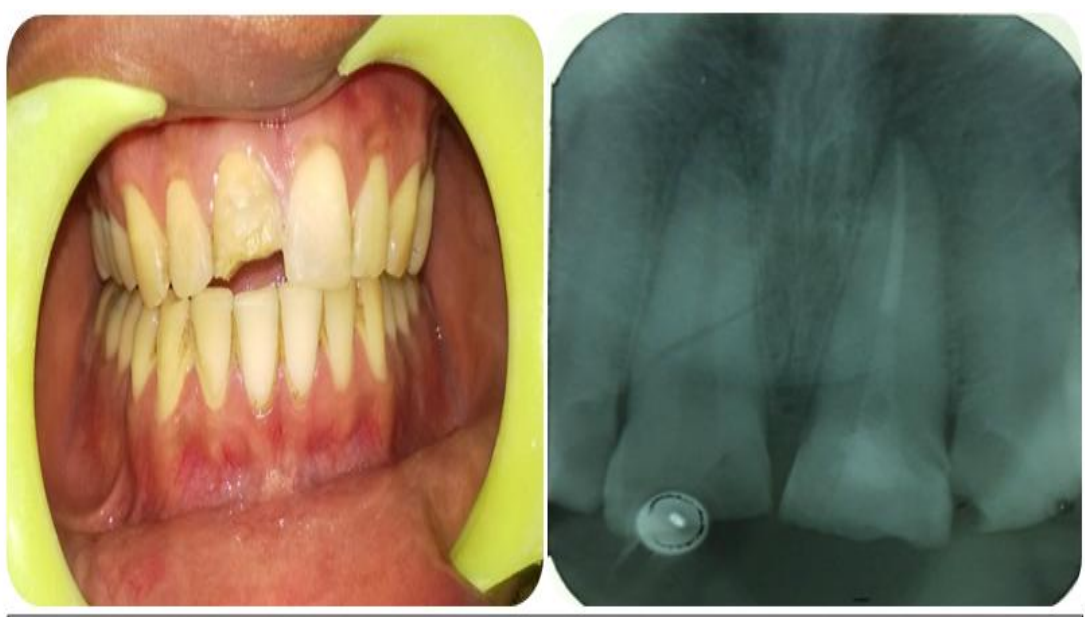

Fig 2 Post operative Clinical and Radiographic view after re-attachment with fiber post in \#11 and composite restoration in \# 12 and \# 21

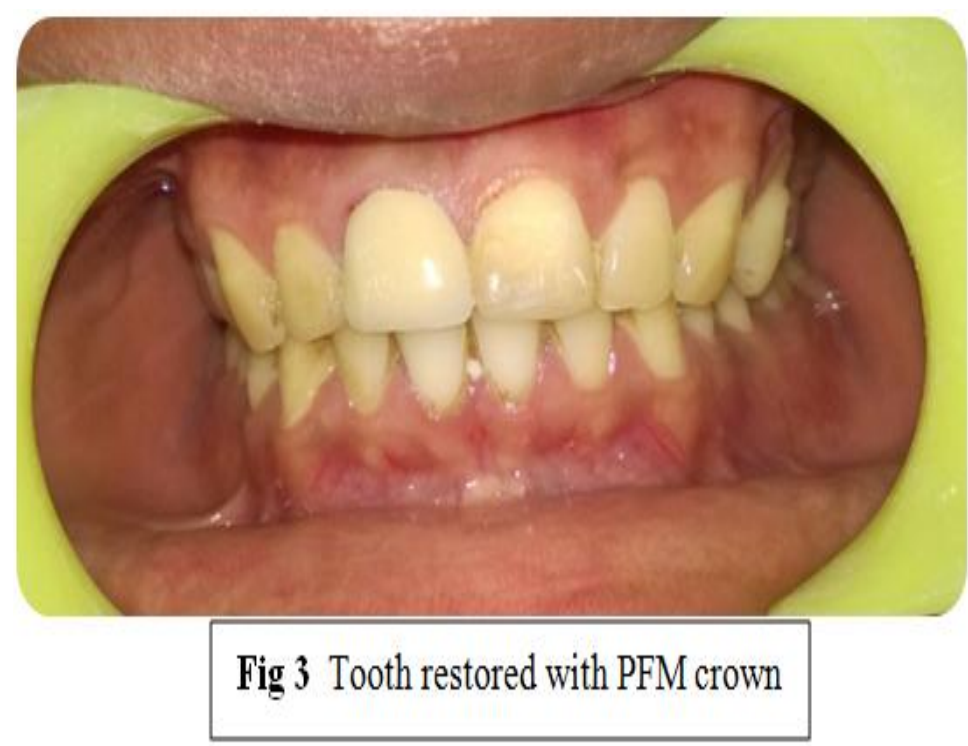

